\title{
Prevalência de tracoma no Município de Miraselva, Estado do Paraná, Brasil
}

\author{
Trachoma prevalence in Miraselva City, Paraná State, Brazil
}

\author{
Ana Tereza Ramos Moreira (1) \\ Marinho Jorge Scarpi (2) \\ Cintia Oyama \\ Rubens Penteado \\ Luciane B. Moreira (4) \\ Tania Guidugli (s)
}

Trabalho realizado pelas Disciplinas de Oftalmologia da Faculdade Evangélica de Medicina do Paraná conjuntamente com a Escola Paulista de Medicina.

(l) Professora Assistente da Disciplina de Oftalmologia daFaculdade Evangélica de Medicina doParaná A luna do curso de Pós-Graduação em Of talmologia daEscola Paulista de Medicina.

(2) Professor Adjunto Doutor, Chefe da Disciplina de Oftalmologia Preventiva e Social, Chefe do Labo ratório de Doenças Externas Oculares da Escola Paulista de Medicina.

(3) Médicos residentes em Oftalmologia da Faculdade Evangélica de Medicina do Pareńr

(4) Acadêmica de Medicina da Faculdade Evangélica de Medicina do Paraná.

(5) Bióloga responsável-técnica do Laboratório de Doenças Externas do Departamento de Oftalmologia da EPM.

Endereço para Correspondência: Dra. Ana Tereza Ramos Moreira - Rua Carlos de Carvalho, 1310 , Curitiba, Paraná - CEP 80730-200.

\begin{tabular}{l} 
RESUMO \\
\hline A prevalência de tracoma no município de Miraselva, Estado do Para- \\
ná, foi estudada de acordo com o sistema de graduação adotado pela \\
Organização Mundial da Saúde (THYLEFORS e cols.,1981). Foram exa- \\
minadas 263 crianças cujas idades variaram entre 6 meses e 15 anos. \\
Encontrou-se $51,7 \%$ de positividade para tracoma folicular, com picos de \\
prevalência de $14,8 \%$ na faixa etária de 2 e 3 anos de idade. Não se \\
encontrou nenhum caso de tracoma folicular intenso, triquíase, cicatriz ou \\
opacidade corneana.
\end{tabular}

Palavras-chave: Tracoma; Chlamydia trachomatis; Prevalência.

INTRODUCÃ̃o

Tracoma é infecção da conjuntiva que atinge aproximadamente $500 \mathrm{mi}$ lhões de pessoas em todo o globo terrestre, sendo que a maioria pertence a comunidades rurais dos países em desenvolvimento, especialmente as regiões áridas tropicais e subtropicais (DAWSON e col.,1981).

O tracoma penetrou no Brasil com imigrantes europeus e asiáticos principalmente no período correspondente aos últimos anos do século passado até a Primeira Guerra Mundial. Os três focos endêmicos primitivos foram o Nordeste, o Estado de São Paulo e Rio Grande do Sul. O foco de São Paulo expandiu-se dentro das fronteiras do Estado, atingindo depois o norte do Paraná pelo deslocamento de trabalhadores para as fazendas de café. Das três regiões endêmicas citadas, a que apresentou maior importância epidemiológica na difusão do tracoma foi a região nordestina, pelo fato que desta área partiam contínuas correntes migratorias de trabalhadores para outras regiões (FREITAS,1967).
O tracoma é conhecido como uma infecção que ocorre entre os membros de uma mesma família, em áreas pouco desenvolvidas do mundo, sendo a infância precoce a faixa etária de maior incidência. A bactéria Chlamydia trachomatis e o agente causador da infecção ocular, sendo os sorotipos $\mathrm{A}, \mathrm{B}, \mathrm{Ba}$, e $C$ os mais freqüentes. A apresentação clínica do tracoma depende de vários fatores, entre os quais, o agente etiológico, reinfecções (TAYLOR e col., 1982), infecções bacterianas superpostas, fatores ambientais e reações do hospedeiro (SCARPI e col.,1989). A severidade do tracoma está associada ao grande número de pessoas habitando uma mesma moradia, as condições de pobreza das mesmas, presença de moscas e abastecimento inadequado de água (DAWSON e col.,1976).

Observações feitas no norte da África sugerem que a prevalência e intensidade do tracoma aumenta com a distância do mar (PROST e col.,1989).

O objetivo do presente trabalho, foi conhecer a atual prevalência de tracoma no município de Miraselva, próximo a cidade de Londrina, norte do 
Estado do Paraná, região que no passado apresentou alta endemicidade desta infecção (FREITAS, 1967).

\section{POPULAC̄̃o, MATERIAL B MÉTODOS}

Um estudo de corte transversal foi realizado no município de Miraselva, norte do Estado do Paraná, cuja população é de 5.940 habitantes, sendo 3.799 de área rural. Ele situa-se a 85 quilômetros de Londrina, que é o pólo industrial e centro de referência de toda a região. A economia de Miraselva é baseada no plantio de cana-de-açúcar, soja, algodão e milho. Neste município, o abastecimento de água não é realizado pela SANEPAR (Companhia de Saneamento do Estado do Paraná), sendo que na área rural, onde reside a maioria das crianças desta região, a água é de poço. O município não possui rede de esgotos, sendo os dejetos escoados, em sua totalidade, por fossa rudimentar (IBGE - Censo 1980).

O estudo da prevalência do tracoma foi realizado durante o mês de fevereiro do ano de 1991, período em que o ano letivo escolar ainda não havia iniciado. Com o auxílio da Secretaria Municipal da Saúde convocamos as crianças, em idade escolar, a participar do estudo através do comparecimento ao local do exame. As crianças em idade pré-escolar foram examinadas nas creches que freqüentavam.

Foram examinados ambos os olhos das 263 crianças participantes do estudo. A faixa etária variou entre 6 meses e 15 anos de idade.

Foi adotado o sistema preconizado pela Organização Mundial da Saúde em 1987 para a classificação clínica dos casos de tracoma (THYLEFORS e col.,1987). Utilizamos lupas binoculares de 2,5 e 4 vezes de magnificação

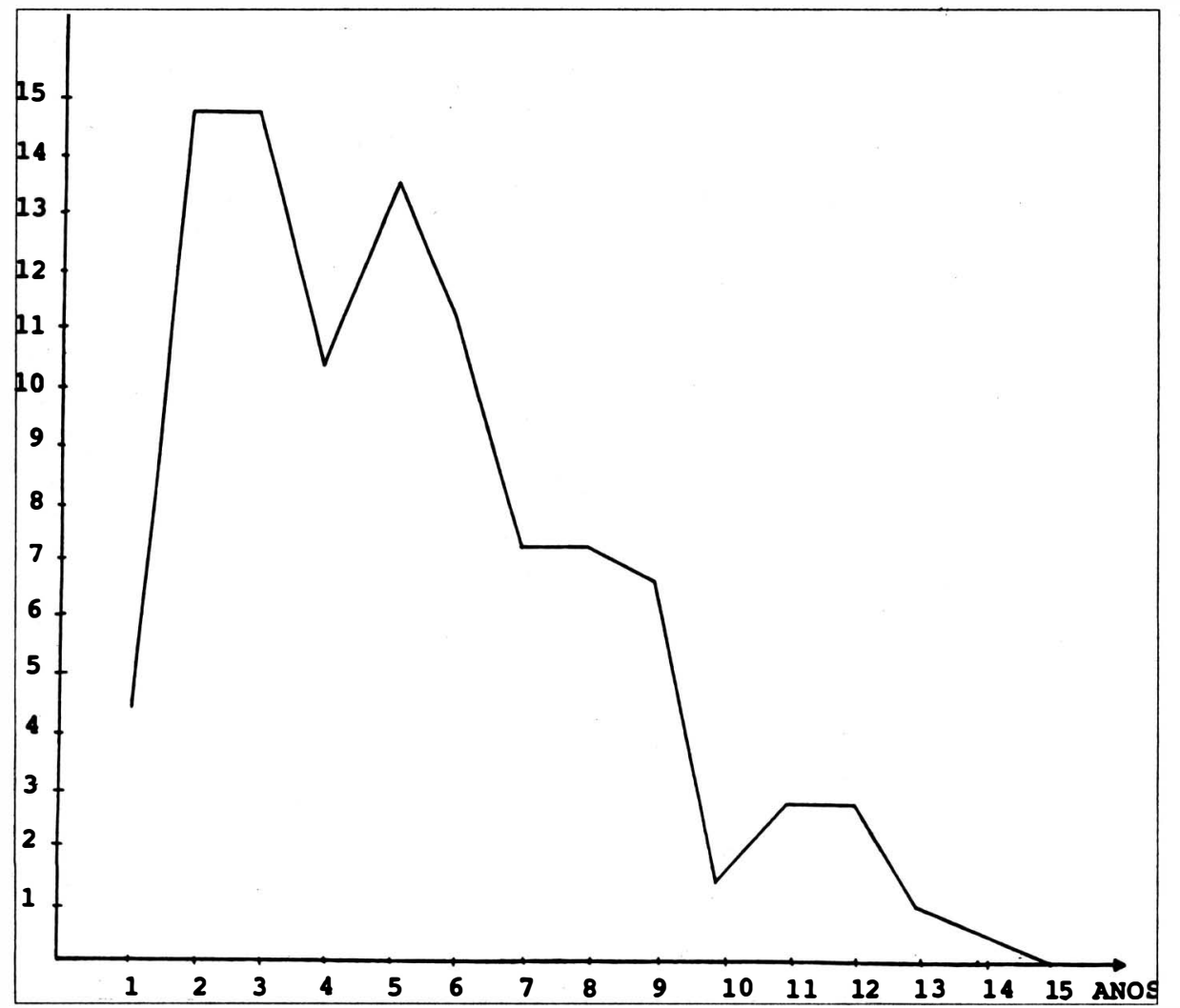

Figura - Curva de prevalência de tracoma folicular segundo a idade em pré-escolares e escolares do município de Miraselva, região norte do estado do Paraná, Brasil, em fevereiro de 1991. para observação da córnea, conjuntiva tarsal superior e verificação do posicionamento dos cílios. $O$ exame foi realizado sob luz solar. Denominou-se Tracoma Folicular (TF) a presença de 5 ou mais folículos visíveis na conjuntiva tarsal superior evertida; se além desses folículos houvesse espessamento inflamatório pronunciado da conjuntiva tarsal superior, que obscurecesse mais da metade dos vasos tarsais profundos normais, a classificação seria de Tracoma Folicular Intenso (TI). Se na área de conjuntiva tarsal superior pudessem ser observadas cicatrizes, a classificação seria de Tracoma Cicatricial (TS). Triquíase Tracomatosa (TT) corresponderia à presença de pelo menos um cílio roçando o globo ocular ou a evidencia de epilação. Se fosse observado alguma opacidade corneana com densidade suficiente para dificultar a visualização de parte da margem pupilar quando vista através da opacidade, o diagnóstico seria de Opacidade Corneana $(\mathrm{CO})$.

\section{RESULTADOS}

Entre as 263 crianças examinadas constatou-se presença de tracoma folicular em 136, ou seja, $51,7 \%$. Nas demais 127 crianças não foi observado nenhum sinal de lesão tracomatosa.

A prevalência de TF, segundo a idade, está representada na figura.

Destas 136 crianças, 82 eram freqüentadoras de creches $(60,3 \%)$ que são mantidas financeiramente pela administração municipal. A idade destas crianças variou entre 1 e 11 anos.

Do total de crianças diagnosticadas clinicamente como portadoras de TF, 60 eram do sexo masculino $(44,1 \%)$ e 76 crianças eram representantes do sexo feminino $(55,9 \%)$.

Não foi encontrado nenhum caso de tracoma folicular intenso, cicatrizes, triquíase ou opacidade comeana.

$\mathrm{Na}$ curva de prevalência dos casos de TF encontrados nesta investigação, constatou-se que a faixa etária entre $2 \mathrm{e}$ 
Prevalência de tracoma no Municipio de Miraselva, Estado do Paraná, Brasil
3 anos apresentou a maior porcentagem de positividade para tracoma folicular $(14,8 \%)$. As crianças com mais de 5 anos apresentaram menor prevalência da infecção.

\section{DISCUSSÃO}

A infecção tracomatosa ocular resulta do contato com as mãos infectadas, roupas ou por moscas contaminadas (DAWSON e col.,1981). Os hábitos de higiene são um dos mais importantes fatores de risco para tracoma. Foi demonstrado, em uma pesquisa realizada no México, que crianças acostumadas a lavar o rosto com freqüência e a usar toalhas individuais apresentaram baixa prevalência de tracoma (TAYLOR e col.,1985). Em nossos resultados obtivemos alta prevalência de tracoma folicular nas crianças com faixa etária de 2 e 3 anos $(14,8 \%)$. Estas crianças freqüentam as creches do município, onde não observamos os cuidados adequados de higiene individualizado para as crianças. Em geral a mesma toalha era utilizada para secar o rosto de várias crianças, o que facilita a transmissão da infecção. Não foram colhidos espécimes para o teste do anticorpo monoclonal fluorescente neste município, sendo que a equipe médica foi treinada para $o$ diagnóstico clínico em outros três municípios vizinhos onde a doença tracomatosa foi confirmada laboratorialmente.

O diagnóstico clínico continua sendo o melhor meio de obtenção da prevalência total do tracoma clínico, pois todos os testes laboratoriais disponíveis subestimam a quantidade de infecção de uma população (WILSON e col., 1986). Todos os casos de TF encontrados nesta investigação foram diagnosticados clinicamente.

A prevalência de tracoma folicular encontrada no presente trabalho foi de $51,7 \%$, considerada bastante elevada quando comparada aos 7,94\% observados no município de Joinvile, Estado de Santa Catarina, e outras localidades das regiões Nordeste e Sudeste (LUNA,
1987; SCARPI,1989; SCARPI e col., 1989; SCARPI e col.,1990; NÓBREGA e cols., 1991).

O município de Miraselva é o mais pobre entre todos os municípios da região onde a prevalência de tracoma já foi estudada (dados não publicados). $\mathrm{Na}$ Tunísia foi observado que o mais pobre entre dois oásis onde a prevalência de tracoma foi estudada, apresentou a maior prevalência da doença (DAWSON e col.,1976). O município de Porecatu está situado a uma distância de 40 quilômetros de Miraselva, possui uma grande usina de cana-de-açúcar em seu território, sendo portanto mais rico. Apesar de não haver sido estudado os fatores sócio-econômicos dos municípios, quando se compara os $51,7 \%$ de TF encontrados em Miraselva com os 20,38\% de TF observados no município de Porecatu, conclui-se que assim como na Tunísia, a prevalência da doença tracomatosa foi maior no $\mathrm{mu}$ nicípio mais pobre.

A grande prevalência de tracoma folicular presente nas crianças de 2 e 3 anos de idade $(14,8 \%)$ classificam Miraselva como área de alta endemicidade, considerando que quanto menor a endemicidade do tracoma, mais elevada será a idade em que aparecerá o pico de prevalência de TF (ASSAD e col.,1968).

O pico de prevalência de tracoma folicular encontrado na curva representativa da prevalência segundo a idade (figura), se deu na faixa etária de 2 a 3 anos, mostrando declínio importante após os 5 anos, sendo que aos 15 anos não foi encontrado nenhum caso de TF, zerando a curva de prevalência nesta faixa etária. De acordo com a literatura, quanto menor for a idade em que aparecer a maior prevalência de TF, mais severo será o comprometimento tracomatoso (DAWSON e cols.,1981). Esta afirmação não coincide com os resultados obtidos no presente trabalho, pois, apesar da maior prevalência ocorrer em baixa idade, não foi diagnosticado nenhum caso de tracoma cicatricial na faixa etária em que foi realizado o exame. No município de Mocambo, Estado do Ceará, a prevalência de TF encontrada foi inferior à por nós obtida neste trabalho, assim como o pico da curva de prevalência de TF ocorreu em idade mais avançada, ou seja, no grupo de 5 a 10 anos. No entanto, em Mocambo foi encontrado opacidades corneanas, caracterizando o tracoma deste município como causador de cegueira.

Tracoma causador de cegueira ocorre em comunidades em que exista perda da acuidade visual decorrente de opacidades corneanas, grande prevalência de triquíase tracomatosa, entrópio e defeitos palpebrais devido a tracoma. Tracoma não causador de cegueira é observado nas comunidades que apresentam baixa prevalência da inflamação conjuntival tracomatosa (DAROUGAR e col., 1983).

A ausência de tracoma folicular intenso, triquíase, cicatrizes e opacidades corneanas nos resultados obtidos neste trabalho, contrasta com a elevada prevalência de tracoma folicular, pico de prevalência da doença em baixa idade e declínio significativo da curva de prevalência de TF a partir dos 5 anos. Isto tudo quando comparados com a região Nordeste do país, que apresenta menor prevalência de TF, porém cegueira presente (SCARPI e col., 1989), mostra a necessidade da continuidade do estudo de prevalência do tracoma em faixa etária superior à estudada, para verificar a presença ou não de opacidades corneanas que possam provocar cegueira neste município, além de constante vigilância epidemiológica.

\section{REFERÊNCIAS BIBLIOGRÁFICAS}

1. ASSAD, F. A.; MAXWELL-LYONS, F.; SUNDARESAN, T. - Use of local variations in trachoma endemicity in Taiwan to elucidate some of the clinical and epidemiological aspects of the disease. Bull. World Health Organ., 39:567-86,1968.

2. DAWSON, C. R.; DAGHFOUS, T.; MESSADI, M.; HOSHIWARA, I.; SCHACHTER, J. - Severe endemic trachoma in Tunisia. Br. J. Ophthalmol., 60:245-52, 1976. 
3. DAWSON, C. R.; JONES, B. R.; TARIZZO, M. L. - Guide to trachoma control in programmes for the prevention of blindness. World Health Onganization, Geneva, 1981, 55p.

4. FREITAS, C. A. - Panorama da endemia tracomatosa no Brasil. Rev. Bras. Malariol. Doenças Trop., 19:185-218, 1967. IBGE. Censo 1980. - In formações Básicas Municipais, 1984.

5. LUNA, E. J.; MEDINA, N. H.; OLIVEIRA, M. B. - Vigilância epidemiológica do tracoma no Estado de São Paulo. Arq. Bras. Oftal., 50:70-9, 1987.

6. NOBREGA, M. J.; BONOMO, P. P.; SCARPI, M. J.; GIUDUGLI, T.; CAMPOS, C. E. G.; JULIANO,Y.; NOVO, N. F. - Prevalência de tracoma em crianças pré-escolares e escolares da periferia da cidade de Joinvile, Estado de Santa
Catarina, Brasil. Invest. Ophthalmol. Vis. Sci., 32:737, 1991.

7. SCARPI, M. J. - Aspectos do tracoma em três povoados do Estado da Bahia. Tese doutorado. Escola Paulista de Medicina, São Paulo, 1989.

8. SCARPI, M. J.; PLUT, R. C. A.; ARRUDA, H. O. - Prevalência de tracoma no povoado de Mocambo, Estado do Ceará, Brasil. Arq. Bras. Oftal., 52:177-9,1989.

9. SCARPI, M. J.; SILVA, R. J. M.; FERREIRA, I. A.; BARBOSA, F. A. C.; PLUT, R. C. A. Prevalência de tracoma em bairro do municipio de Palmares, Estado de Pernambuco, Brasil. Arq Bras. Oftal., 53:171-4, 1990.

10. TAYLOR, H. R.; JOHNSON, S. L.; PRENDERGAST, R. A.; SCHACHTER, J.; DAWSON, C. R.; SIL VERSTEIN, A. M. - An animal model of trachoma II. The importance of repeated reinfection. Invest. Ophthalmol. Vis. Sci., 23:507, 15, 1982.

11. TAYLOR, H. R.; VELASCO, F. M.; SOMMER, A. -The ecology of trachoma: an epidemiological study in southem Mexico. Bull World Health Organ., 63:559, 1985.

12. TYLEFORS, B.; DAWSON, C. R.; JONES, B. R.; WEST, S. K.; TAYLOR, H. R.- A simple system for the assessment of trachoma and its complications. Bull World Health Organ. 65:477-83, 1987.

13. WILSON, M. C.; MILLAN-VELASCO, F.; TIELSCH, J. M.; TAYLOR, H. R. - Direct smear fluorescent antibody cytology as a field diag nostic tool for trachoma. Arch. Ophthalmol. 104:688-90, 1986.

\section{EXAME PARA OBTENÇÃO dO TÍTULO DE ESPECIALISTA EM OFTALMOLOGIA}

O Con'selho Brasileiro de Oftalmologia informa que o próximo Exame de Habilutaçäo ao Título de Especialsta em Oftalmologia será em Brasilia por ocasião doXICongresso Brasileiro de Prevenção da Cegueira, 03 à 06 de setembro de 1994.

O EXAME constará de duas partes, ambas eliminatórias:

Prova escrita:

Prova pratica:

Nota minima:

Podera se candidatar:

INSCRIÇÃO:

Observaçao:

Maiores informaçōes: Secretaria Geral do CBO

Fones: (011) 285-4046 e 283-2692

Fax: (011) 285-4509

Al. Santos, 1343/1109

$01414-001$ - São Paulo - SP. 